\title{
A Simple Approach to the Visible-light Photo-activation of Molecular Metal Oxides
}

Satomi Fujimoto, ${ }^{1}$ Jamie M. Cameron, ${ }^{1}$ Rong-Jia Wei, ${ }^{1}$ Katharina Kastner, ${ }^{2}$ David Robinson, ${ }^{3}$ Victor Sans, ${ }^{4,5}$ Graham N. Newton ${ }^{2}$ * and Hiroki Oshio ${ }^{1, *}$

${ }^{1}$ Graduate School of Pure and Applied Sciences, University of Tsukuba, Tennodai 1-1-1, Tsukuba, 305-8571, Japan

${ }^{2}$ School of Chemistry, University of Nottingham, University Park, Nottingham, NG7 2RD, UK

${ }^{3}$ Department of Chemistry and Forensics, School of Science and Technology, Nottingham Trent University, Clifton Lane, Nottingham, NG11 8NS, UK

${ }^{4}$ GSK Carbon Neutral Laboratory, University of Nottingham, Nottingham, NG8 2GA, UK

${ }^{5}$ Faculty of Engineering, University of Nottingham, University Park, Nottingham, NG7 2RD, UK

KEYWORDS: Polyoxometalates, Photocatalysis, Visible Light, Photochemistry, Electrochemistry, Hybrid materials, Redox Chemistry, Density Functional Theory. 


\section{ABSTRACT}

This study explores a new method to maximise the visible-light driven photocatalytic performance of organic-inorganic hybrid polyoxometalates (POMs). Experimental and theoretical investigations of a family of phosphonate substituted POMs shows that modification of grafted organic moieties can be used to tune the electronic structure and photo-activity of the metal oxide component. Unlike fully inorganic polyoxotungstates, these organic-inorganic hybrid species are responsive to visible-light and function as photocatalysts $(\lambda>420 \mathrm{~nm})$ in the decomposition of a model environmental pollutant. The degree of photo-activation is shown to be dependent on the nature of the inductive effect exerted by the covalently-grafted substituent groups. This study emphasises the untapped potential that lies in an orbital engineering approach to hybrid-POM design and helps to underpin the next generation of bespoke, robust and costeffective molecular metal oxide photo-active materials and catalysts.

\section{INTRODUCTION}

The effective use of solar energy to drive commercially important and/or challenging reactions and processes has long been a key target in chemical research, with potential applications ranging from selective organic transformations ${ }^{1-3}$ to the widespread, sustainable generation of carbon-neutral 'solar fuels'. ${ }^{4,5}$ Whilst much of this effort has traditionally involved the use of heterogeneous, solid-state semiconducting materials such as titanium and tungsten oxides, ${ }^{6-8}$ molecular photocatalysts have become increasingly attractive due to their versatility, homogeneity and tuneable properties. ${ }^{9-12}$ Here, we show how a modular design approach to the 
generation of molecular photocatalysts allows for the tuning and optimisation of photocatalytic performance under visible-light.

Polyoxometalates (POMs) are a promising group of photo-active, nanoscale metal-oxide clusters composed of early transition metals in their highest oxidation states $\left(\right.$ i.e. $\mathrm{V}^{\mathrm{V}}, \mathrm{Mo}^{\mathrm{VI}}, \mathrm{W}^{\mathrm{VI}}$ ). POMs display a variety of appealing properties, including a wide range of potential structures and compositions, excellent stability and tuneable solubility in a range of solvents. ${ }^{13,14}$ In particular, their ability to undergo reversible, often proton-coupled, multi-electron redox processes has generated considerable interest in their application as novel electron-transfer catalysts and redox mediators. ${ }^{15,16}$ POMs also exhibit rich photochemistry that can be accessed through excitation of the $\mathrm{O} \rightarrow \mathrm{M}$ ligand-to-metal charge transfer (LMCT) band. ${ }^{17,18}$ This results in the formation of a short-lived charge-separated state at the terminal $\mathrm{M}=\mathrm{O}$ positions on the metal-oxide shell, comprising mono-reduction of the POM core and a highly reactive oxocentred radical cation, capable of participating in a variety of oxidation and hydrogen-transfer reactions. ${ }^{19-21}$ This photo-activity is, however, restricted by the energy of the LMCT band which usually falls well within the UV-region of the spectrum (typically at wavelengths of 300-330 $\mathrm{nm}) .{ }^{18}$

Significantly, POMs can be modified to form meta-stable lacunary derivatives, in which one or more metal centres are hydrolytically removed to generate reactive, multi-dentate vacancies in the metal-oxide shell. ${ }^{22,23}$ This provides almost limitless opportunity for the design, synthesis and post-synthetic modification of functional POM-based materials, ${ }^{24-27}$ and a growing body of work has shown how this can be used to graft organic or organometallic moieties directly onto the POM core to form organic-inorganic hybrid systems. ${ }^{28-32}$ Modification with chromophores possessing absorption bands in the visible range of the spectrum allows the generation of visible- 
light sensitive hybrid-POMs that can exhibit intra-molecular charge transfer from the photoactive antennae to the inorganic POM core. ${ }^{33-35}$ POM photochemistry can therefore be grouped into two branches: (i) excitation of the POM LMCT band to yield the oxo radical, and (ii) photodriven intramolecular 'exo'-charge transfer from covalently grafted chromophores. Each photoinduced charge transfer process proceeds via contrasting mechanisms and can thus be expected to show very different reactivities. Whilst the latter has proven effective in applications which rely on charge accumulation on, and/or electron transfer from the POM (such as hydrogen evolution), ${ }^{36-39}$ it circumvents formation of the highly oxidizing oxo-radical on the metal-oxide shell (which generally remains accessible only under UV irradiation). Existing hybridization approaches to photo-activation therefore preclude the use of POMs as powerful visible light driven photo-oxidation catalysts and new approaches to the direct photosensitization of the POM core are therefore an attractive ongoing goal.

Recently, we reported that hybridization of a Wells-Dawson-type POM with organophosphonate moieties could be used to directly photo-activate the POM, as demonstrated in the visible-light driven oxidative decomposition of a model environmental pollutant. ${ }^{40}$ Analysis of the resulting organic-inorganic hybrid cluster: $\mathrm{K}_{6}\left[\mathrm{P}_{2} \mathrm{~W}_{17} \mathrm{O}_{61}\left(\mathrm{P}(=\mathrm{O}) \mathrm{C}_{6} \mathrm{H}_{5} \mathrm{CO}_{2} \mathrm{H}\right)_{2}\right](\mathbf{1})$ (Figure 1), suggested that grafting of the organophosphonate groups onto the POM was an effective means to alter both the electrochemical properties and photochemical reactivity of the POM core. We postulated that the charge density on the metal-oxide shell is lowered as a result of the hybridization, modulating the energies of the frontier orbitals associated with the key photo-excitation and $1^{\text {st }}$ reduction processes. Here, we explore the nature of this phenomena by modifying the electronic character of appended ligand groups demonstrate how this hybridization strategy allows the visible light photo-activity of POMs to be both accessed and, 

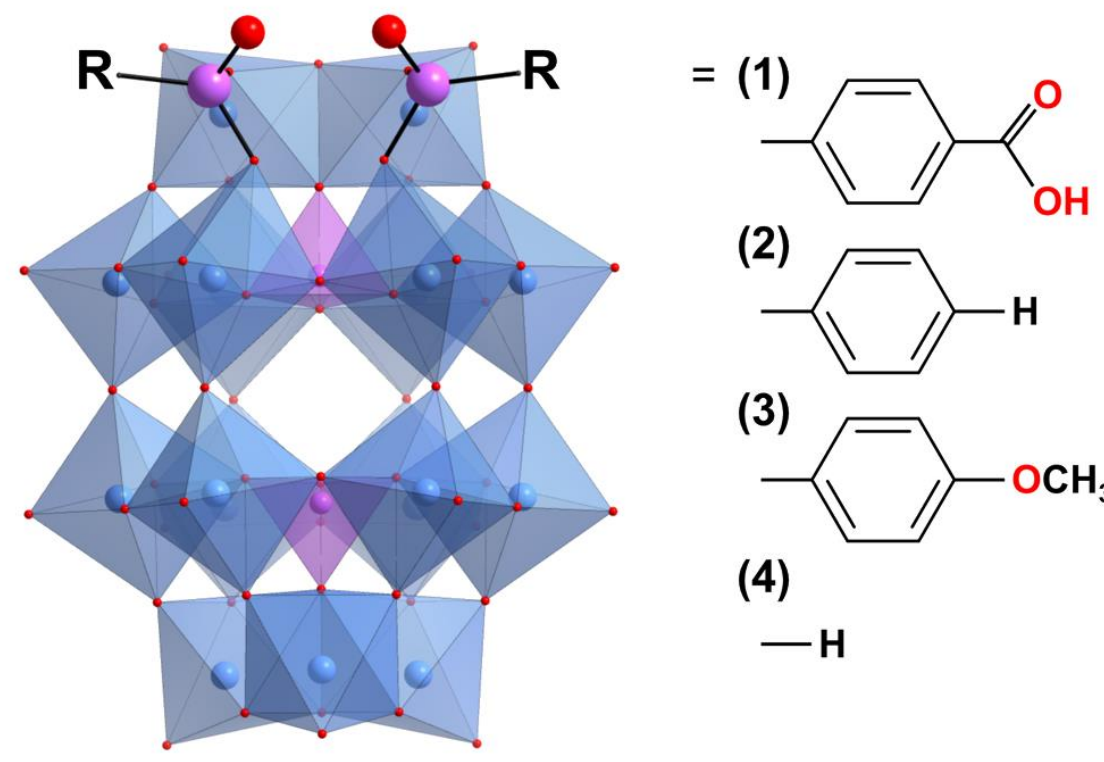

(2)

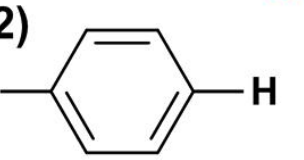

(3)

(4)

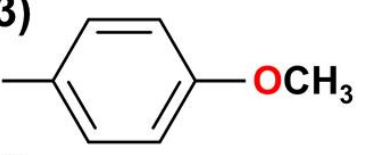

$-\mathbf{H}$

Figure 1. Structural representation of phosphonate-substituted POM clusters 1-4, showing the structure of the polyoxometalate core (left) and the different substituent groups appended to the phosphonate moieties in each complex (right). Colour code: $\left\{\mathrm{WO}_{6}\right\}$ polyhedra $=$ blue; $\left\{\mathrm{PO}_{4}\right\}$ polyhedra $=$ pink, $\mathrm{O}=$ red, $\mathrm{P}=$ pink.

uniquely, show that it can be systematically tuned, providing a new path towards the application of metal-oxide clusters in next generation solar-fuel and photochemical technologies.

\section{EXPERIMENTAL SECTION}

\section{Synthesis and Materials}

All reagents were obtained from commercial sources and were used without further purification.

The precursors 4-carboxyphenyl phosphonic acid, ${ }^{41} \mathrm{~K}_{6}\left[\mathrm{P}_{2} \mathrm{~W}_{18} \mathrm{O}_{62}\right] \cdot 14 \mathrm{H}_{2} \mathrm{O}$ and $\mathrm{K}_{10}\left[\mathrm{P}_{2} \mathrm{~W}_{17} \mathrm{O}_{61}\right] \cdot 20 \mathrm{H}_{2} \mathrm{O}$ were prepared by reported methods. ${ }^{42}$ 
$\mathrm{K}_{6}\left[\mathrm{P}_{2} \mathrm{~W}_{17} \mathrm{O}_{61}\left(\mathrm{POC}_{6} \mathrm{H}_{4} \mathrm{COOH}\right)_{2}\right] \cdot 6 \mathrm{C}_{4} \mathrm{H}_{9} \mathrm{NO}$ (1) was synthesized according to our previously reported protocol. ${ }^{40}$

$\mathrm{K}_{5} \mathrm{H}_{[}\left[\mathrm{P}_{2} \mathrm{~W}_{17} \mathrm{O}_{61}\left(\mathrm{POC}_{6} \mathrm{H}_{5}\right)_{2}\right] \cdot 4 \mathrm{C}_{4} \mathrm{H}_{9} \mathrm{NO}$ (2) was synthesized following the method reported for compound 1: $\mathrm{K}_{10}\left[\mathrm{P}_{2} \mathrm{~W}_{17} \mathrm{O}_{61}\right] \cdot 20 \mathrm{H}_{2} \mathrm{O}(984 \mathrm{mg}, 0.2 \mathrm{mmol}$ ), phenyl phosphonic acid (63.3 $\mathrm{mg}$, $0.4 \mathrm{mmol})$ and $\mathrm{KCl}(126 \mathrm{mg}, 1.7 \mathrm{mmol})$ were suspended in $N, N^{\prime}$-dimethylacetamide $(30 \mathrm{~mL})$ and $12 \mathrm{M} \mathrm{HCl}(100 \mu \mathrm{L})$ was then added. The reaction mixture was then heated at $90^{\circ} \mathrm{C}$ for 24 hours and after cooling to room temperature, the reaction mixture was filtered to give a green solution. Subsequent centrifugation with diethylether, ethanol and diethylether gave $\mathbf{2}$ as a green powder. Yield: $880 \mathrm{mg}(90 \%$ based on W).

Single crystals of 2 could be grown by dissolution of $100 \mathrm{mg}$ powder in acetonitrile:water solution $(6: 1 \mathrm{v} / \mathrm{v}, 10 \mathrm{~mL})$, followed by slow evaporation of the resultant solution at room temperature to yield single crystals of compound 2 after $c a .2$ weeks (yield $=14.3 \mathrm{mg}, 14 \%$ ). Crystallographic data for compound 2: $\mathrm{C}_{36} \mathrm{H}_{85} \mathrm{~K}_{10} \mathrm{~N}_{3} \mathrm{O}_{147} \mathrm{P}_{8} \mathrm{~W}_{34} ; M_{\mathrm{r}}=9801.4 \mathrm{~g} \mathrm{~mol}^{-1}$; triclinic; space group P-1; $Z=2 ; \mathrm{a}=16.741(1) \AA ; \mathrm{b}=24.568(2) \AA ; \mathrm{c}=25.667(2) \AA ; \alpha=115.585(1)^{\circ} ; \beta=$ $100.543(1)^{\circ} ; \gamma=101.934(1)^{\circ} ; \mathrm{V}=8864.7(12) \AA^{3}$.

${ }^{1} \mathrm{H}$ NMR (DMSO- $\left.d_{6}, 400 \mathrm{MHz}\right): \delta / \mathrm{ppm}=7.48(\mathrm{~m}, 4 \mathrm{H}), 7.53(\mathrm{~d}, 2 \mathrm{H}), 7.99(\mathrm{dd}, 4 \mathrm{H}) .{ }^{31} \mathrm{P}$ NMR $\left(\mathrm{DMSO}-d_{6}, 400 \mathrm{MHz}\right): \delta / \mathrm{ppm}=14.84,-11.34,-12.96 . \mathrm{IR}\left(\mathrm{KBr}, \mathrm{cm}^{-1}\right): 1612\left(\mathrm{~s}, v_{\mathrm{C}}=\mathrm{C}\right), 1400(\mathrm{~m}$, $\left.v_{\mathrm{C}=\mathrm{C}}\right), 1194\left(\mathrm{~s}, v_{\mathrm{W}=0}\right), 1045\left(\mathrm{~s}, v_{\mathrm{W}=0}\right), 962\left(\mathrm{~s}, v_{\mathrm{W}=0}\right), 912\left(\mathrm{~s}, v_{\mathrm{W}=0}\right), 816\left(\mathrm{~s}, v_{\mathrm{W}=0}\right) \mathrm{cm}^{-1}$. Elemental analysis: calcd. (\%) for $\mathrm{C}_{28} \mathrm{H}_{47} \mathrm{~K}_{5} \mathrm{~N}_{4} \mathrm{O}_{67} \mathrm{P}_{4} \mathrm{~W}_{17}$ : K 3.94, $\mathrm{H}$ 0.96, C 6.79, $\mathrm{N} 1.13$; found $\mathrm{K} 4.14, \mathrm{H}$ 0.93, C $6.52, \mathrm{~N} 1.19$. 
$\mathrm{K}_{6}\left[\mathrm{P}_{2} \mathrm{~W}_{17} \mathrm{O}_{61}\left(\mathrm{POC}_{6} \mathrm{H}_{4} \mathrm{OCH}_{3}\right)_{2}\right] \cdot \mathbf{4 C}_{4} \mathrm{H}_{9} \mathrm{NO}$ (3) was synthesized following the method reported for compound 1: $\mathrm{K}_{10}\left[\mathrm{P}_{2} \mathrm{~W}_{17} \mathrm{O}_{61}\right] \cdot 20 \mathrm{H}_{2} \mathrm{O}$ (1094.5 mg, $\left.0.22 \mathrm{mmol}\right)$, 4-methoxyphenyl phosphonic acid (83.8 $\mathrm{mg}, 0.44 \mathrm{mmol})$ and $\mathrm{KCl}(149 \mathrm{mg}, 2 \mathrm{mmol})$ were suspended in $N, N^{\prime}-$ dimethylacetamide $(30 \mathrm{~mL})$ and $12 \mathrm{M} \mathrm{HCl}(100 \mu \mathrm{L})$ was then added. The reaction mixture was then heated at $90^{\circ} \mathrm{C}$ for 24 hours and after cooling to room temperature, the reaction mixture was filtered to give a green solution. Subsequent centrifugation with diethylether, ethanol and diethylether gave 3 as an orange powder. Yield: $829.1 \mathrm{mg}$ (76\% based on W).

Single crystals of 3 could be grown by dissolution of $100 \mathrm{mg}$ powder in acetonitrile:water solution $(6: 1 \mathrm{v} / \mathrm{v}, 10 \mathrm{~mL})$, followed by slow evaporation of the resultant solution at room temperature to yield single crystals of compound 3 after $c a .2$ weeks (yield = $20.1 \mathrm{mg}, 20 \%$ ). Crystallographic data for compound 3: $\mathrm{C}_{18} \mathrm{H}_{28.5} \mathrm{~K}_{6} \mathrm{~N}_{1.5} \mathrm{O}_{68.5} \mathrm{P}_{4} \mathrm{~W}_{17} ; M_{\mathrm{r}}=4845.85 \mathrm{~g} \mathrm{~mol}^{-1}$; triclinic; space group P-1; $Z=2 ; \mathrm{a}=13.829(1) \AA ; \mathrm{b}=15.550(1) \AA ; \mathrm{c}=23.417(2) \AA ; \mathrm{a}=100.864(1)^{\circ} ; \mathrm{b}=$ $95.540(1)^{\circ} ; \mathrm{c}=113.092(1)^{\circ} ; \mathrm{V}=4467.2(6) \AA^{3}$.

${ }^{1} \mathrm{H}$ NMR (DMSO- $\left.d_{6}, 400 \mathrm{MHz}\right): \delta / \mathrm{ppm}=3.83(\mathrm{~s}, 6 \mathrm{H}), 7.02(\mathrm{dd}, 4 \mathrm{H}), 7.91(\mathrm{dd}, 4 \mathrm{H}) .{ }^{31} \mathrm{P}$ NMR $\left(\mathrm{DMSO}-d_{6}, 400 \mathrm{MHz}\right): \delta / \mathrm{ppm}=15.85,-11.37,-12.99 . \mathrm{IR}\left(\mathrm{KBr}, \mathrm{cm}^{-1}\right): 1599\left(\mathrm{~s}, v_{\mathrm{C}=\mathrm{C}}\right), 1193(\mathrm{~s}$, $\left.v_{\mathrm{W}=\mathrm{O}}\right), 962\left(\mathrm{~s}, v_{\mathrm{W}=\mathrm{O}}\right), 914\left(\mathrm{~s}, v_{\mathrm{W}=\mathrm{O}}\right), 816\left(\mathrm{~s}, v_{\mathrm{W}=\mathrm{O}}\right) \mathrm{cm}^{-1}$. Elemental analysis: calcd. (\%) for $\mathrm{C}_{20} \mathrm{H}_{39.5} \mathrm{~K}_{6} \mathrm{~N}_{1.5} \mathrm{O}_{72.5} \mathrm{P}_{4} \mathrm{~W}_{17}: \mathrm{K} 4.74, \mathrm{H} 0.81, \mathrm{C} 4.86, \mathrm{~N} \mathrm{0.42}$; found $\mathrm{K} 4.55, \mathrm{H} 0.82, \mathrm{C} 4.92, \mathrm{~N}$ 0.49 .

$\mathrm{K}_{5} \mathrm{H}_{[}\left[\mathrm{P}_{2} \mathrm{~W}_{17} \mathrm{O}_{61}(\mathrm{POH})_{2}\right] \cdot \mathbf{5 C}_{4} \mathrm{H}_{9} \mathrm{NO}$ (4) was synthesized following the method reported for compound 1: $\mathrm{K}_{10}\left[\mathrm{P}_{2} \mathrm{~W}_{17} \mathrm{O}_{61}\right] \cdot 20 \mathrm{H}_{2} \mathrm{O}$ (982.9 $\left.\mathrm{mg}, 0.2 \mathrm{mmol}\right)$, phosphonic acid (32.8 $\mathrm{mg}$, 
$0.4 \mathrm{mmol})$ and $\mathrm{KCl}(298.2 \mathrm{mg}, 4 \mathrm{mmol})$ were suspended in $N, N^{\prime}$-dimethylacetamide $(30 \mathrm{~mL})$ and $12 \mathrm{M} \mathrm{HCl}(100 \mu \mathrm{L})$ was then added. The reaction mixture was then heated at $90^{\circ} \mathrm{C}$ for 24 hours and after cooling to room temperature, the reaction mixture was filtered to give a green solution. Subsequent centrifugation with diethylether, ethanol and diethylether gave $\mathbf{4}$ as a green powder. Yield: $809.8 \mathrm{mg}(83 \%$ based on $\mathrm{W})$.

Note that in the case of $\mathbf{4}$, it did not prove possible to recrystallize the powdered material to yield single crystals of sufficient quality for X-ray crystallographic analysis.

${ }^{31} \mathrm{P}$ NMR (DMSO- $\left.d_{6}, 400 \mathrm{MHz}\right): \delta / \mathrm{ppm}=4.54,-11.28,-12.91 . \mathrm{IR}\left(\mathrm{KBr}, \mathrm{cm}^{-1}\right): 1196\left(\mathrm{~s}, \mathrm{v}_{\mathrm{W}=0}\right)$, $1092\left(\mathrm{~s}, v_{\mathrm{W}=0}\right), 972\left(\mathrm{~s}, v_{\mathrm{W}=0}\right), 916\left(\mathrm{~s}, v_{\mathrm{W}=0}\right), 816\left(\mathrm{~s}, v_{\mathrm{W}=0}\right) \mathrm{cm}^{-1}$. Elemental analysis: calcd. (\%) for $\mathrm{C}_{20} \mathrm{H}_{48} \mathrm{~K}_{5} \mathrm{~N}_{5} \mathrm{O}_{68} \mathrm{P}_{4} \mathrm{~W}_{17}$ : K 4.0, H 0.99, C 4.91, N 1.43; found $\mathrm{K} 4.25, \mathrm{H}$ 0.99, C 4.73, N 1.43.

\section{Single Crystal X-Ray Diffraction Measurements}

SC-XRD measurements were performed on a Bruker SMART Apex II CCD diffractometer with Mo-K $\alpha$ radiation $(\lambda=0.71073 \AA)$. In each case, a suitable single crystal was removed from the mother liquor and mounted in Paratone ${ }^{\circledR}$ oil on a glass fibre and measured at $100 \mathrm{~K}$ under a stream of dry $\mathrm{N}_{2}$. Structures were solved by direct methods and refined by a full-matrix leastsquares technique on $\mathrm{F}^{2}$ using SHELLXTL. ${ }^{43}$

For compound 2, the PLATON SQUEEZE protocol was used to account for unassigned electron density in the crystal lattice associated with disordered solvent molecules which could not be modeled as discrete atomic positions. ${ }^{44}$ Approximately $33.3 \%$ of the unit cell volume comprises a large region of disordered solvent that could not be modeled as discrete atomic sites. SQUEEZE estimated a total count of 848.5 electrons per unit cell which were assigned to $2.5 \mathrm{~K}$ cations, 9 water and 1.5 DMA molecules per cluster unit. 
For compound 3, approximately $30.0 \%$ of the unit cell volume comprises a large region of disordered solvent that could not be modeled as discrete atomic sites. SQUEEZE estimated a total count of 344.5 electrons per unit cell which were assigned to $4 \mathrm{~K}$ cations, 0.5 water and 1.5 DMA molecules per cluster.

\section{Computational Details}

The geometries of compounds 1-4 were optimized using density functional theory (DFT) with the BP86 functional ${ }^{45,46}$ and LANL2DZ basis set / pseudopotential. ${ }^{47}$ Solvation effects were accounted for using the polarizable continuum model (PCM), with standard van der Waals' radii for all atoms from Q-Chem, except W, for which a VDW radius of 2.1 Angstrom wa employed.

Energetics were further refined using the SRSC basis set / pseudopotential. ${ }^{48}$ Time-dependent DFT (TDDFT) calculations were performed with the same functional, basis set and solvation parameters. All calculations were performed with the Q-Chem software. ${ }^{49}$

\section{Analytical Methods}

Full details of all experimental methods and additional characterization can be found in the accompanying supplementary information.

\section{RESULTS AND DISCUSSION}

\section{Computational Screening of the Initial Concept}

Qualitative in silico screening was used to efficiently explore our initial concept of tuning the electronic properties of the POM via modification of ligand effects. Preliminary calculations 


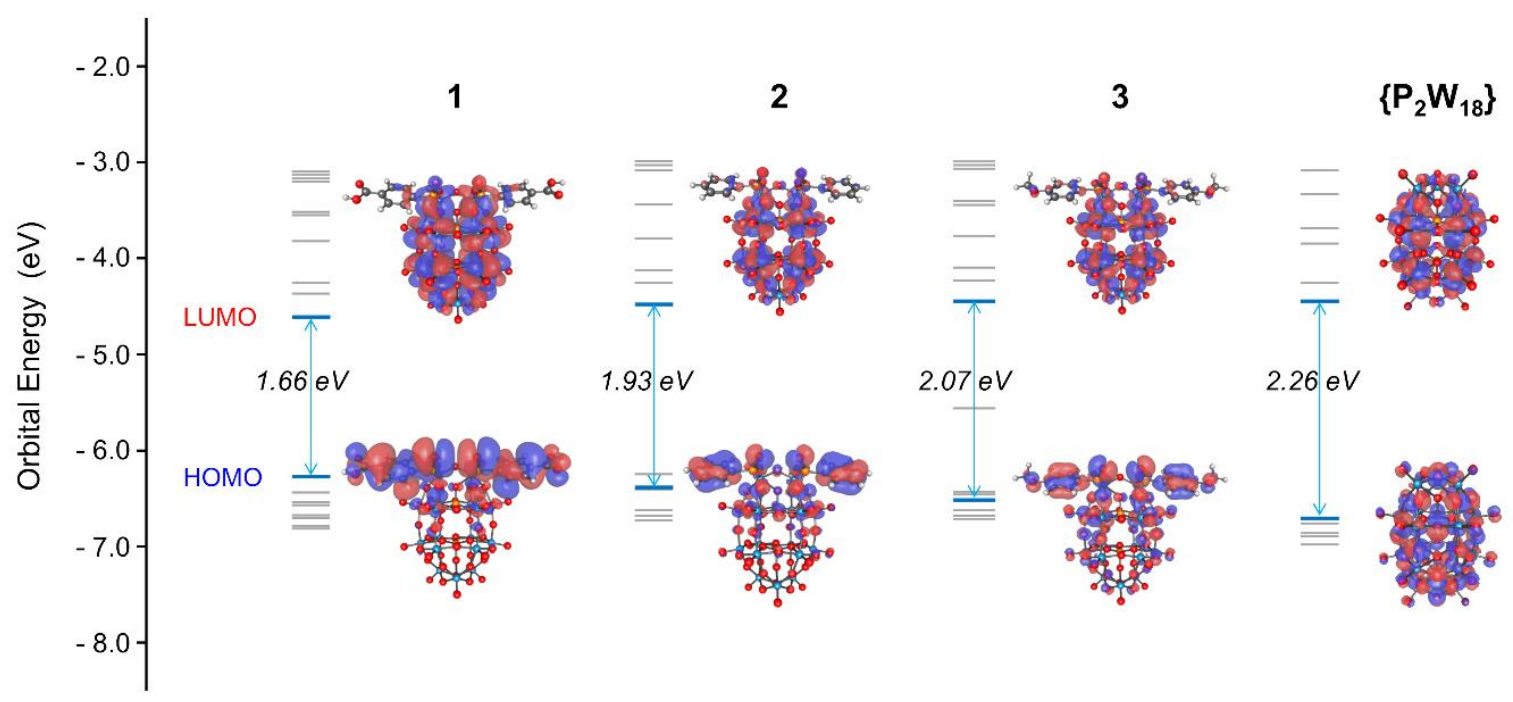

Figure 2. Calculated energy levels of the frontier orbitals in compounds 1-3, shown against those calculated for the analogous parent compound $\left\{\mathrm{P}_{2} \mathrm{~W}_{18}\right\}$ as a comparison. Note that the HOMO level used to demonstrate the energy of the effective HOMO-LUMO gap is not always the HOMO state and instead has been chosen as the highest energy level which contains an appreciable degree of POM-centred orbital character (HOMOPOM, highlighted in blue) and specifically, those with electron density on the p-orbitals of the terminal oxo-groups (see main text for additional detail).

using a density functional theory (DFT) approach (geometry optimisation with BP86/LANL2DZ ${ }^{46,47,50}$ and energy refinement with BP86/SRSC) ${ }^{46,48,50}$ were applied to screen two simulated hybrid complexes against the previously reported carboxylate functionalized cluster, 1, and the parent oxoanion $\left[\mathrm{P}_{2} \mathrm{~W}_{18} \mathrm{O}_{62}\right]^{6-} \quad\left(\left\{\mathbf{P}_{2} \mathbf{W}_{18}\right\}\right)$. These complexes; $\left[\mathrm{P}_{2} \mathrm{~W}_{17} \mathrm{O}_{61}\left(\mathrm{P}(=\mathrm{O}) \mathrm{C}_{6} \mathrm{H}_{5}\right)_{2}\right]^{6-}$ (2) and $\left[\mathrm{P}_{2} \mathrm{~W}_{17} \mathrm{O}_{61}\left(\mathrm{P}(=\mathrm{O}) \mathrm{C}_{6} \mathrm{H}_{4} \mathrm{OCH}_{3}\right)_{2}\right]^{6-}$ (3) were selected as a 
convenient means to explore the effect that the electron withdrawing/donating character of different para-substituents on the phenyl group might have on the metal-oxide core. This allowed questions about the nature of the activation effect to be assessed, most crucially by addressing whether the appended organic groups can be tailored to modulate the properties of the POM itself or whether such activation arises as a general property of complexation with any organophosphonate species. As a representative comparison to the simulated hybrid species, $\left\{\mathbf{P}_{2} \mathbf{W}_{18}\right\}$ was selected over the 'true' lacunary parent species, $\left[\mathrm{P}_{2} \mathrm{~W}_{17} \mathrm{O}_{61}\right]^{10-}\left\{\mathbf{P}_{2} \mathbf{W}_{17}\right\}$, as the "simplified molecular charge density" $(q / m$, where $q=$ cluster charge and $m=$ number of addenda metal centres) ${ }^{51}$ of $\left\{\mathbf{P}_{2} \mathbf{W}_{18}\right\}$ is more directly comparable to that of the equivalently charged hybrid POMs.

Preliminary DFT calculations are presented in Figure 2 (tabulated fully in the SI) and reveal a clear substituent effect on moving from a group with strong electron withdrawing character, as in 1, to that with commensurate electron donating character, as in $\mathbf{3}$. As expected, the HOMOLUMO energy gap (HLgap) and LUMO energy of compound $\mathbf{2}$ are found to be intermediate between 1 and 3. In each case, the hybrid complexes show stabilized LUMO and destabilized HOMO energies with respect to $\left\{\mathbf{P}_{\mathbf{2}} \mathbf{W}_{\mathbf{1 8}}\right\}$, owing to the combination of inductive and resonance effects arising from complexation with the ligand groups.

These calculations also show that the frontier energy levels in all three hybrid complexes have significantly mixed orbital character between the ligand and POM core, where the highest energy occupied states are generally ligand-centered. As a result, the $\mathrm{HL}_{\mathrm{gap}}$ energies reported in Figure 2 do not represent the 'true' (i.e. HOMO to LUMO) transition energy but rather the transition between the highest energy HOMO state containing an appreciable degree of POM-centered orbital character (HOMOPOM, which is found at the HOMO, HOMO-2 and HOMO-3 levels in 
the case of compounds 1-3, respectively). (details are given in the SI). The transition energies were calculated using time-dependent density functional theory (TDDFT), which indicated that several closely spaced transitions contribute to the convoluted broad LMCT band observed in the experimental absorption spectra. Localized $\pi \rightarrow \pi^{*}$ transitions have an oscillator strength two to three orders of magnitude larger than the POM-centered $\mathrm{O} \rightarrow \mathrm{W}$ LMCT transitions, and thus we can differentiate between organic-centered and POM-centered transitions based on the oscillator strength. $^{52}$ This is significant because, as discussed above, the optical transition of interest is the exclusively POM-centered $\mathrm{O} \rightarrow \mathrm{W}$ LMCT band (corresponding to charge transfer from the $2 \mathrm{p}$ orbitals on the terminal oxo-groups to the vacant $5 \mathrm{~d}$ orbitals on the addenda $\mathrm{W}$ atoms). Based on our previous findings, ${ }^{40}$ intramolecular charge transfer from the ligand groups to the POM core is not expected to occur in these compounds.

These results therefore strongly suggest that ligand character can be used to directly modify the frontier orbital energies of the hybrid POM complex and thus alter its electrochemical and photochemical reactivity. As a result, the calculated trend in LUMO energies could subsequently be validated experimentally (see below) and has clear implications in the targeted molecular design of the next generation of (photo)catalytically active POMs.

\section{Synthesis and Characterization of Hybrid Polyoxometalates}

Following theoretical validation of the hypothesis that ligand substituent effects could be translated to the electronic structure of molecular metal oxides, we proceeded with the synthesis of hybrid POM complexes 2 and 3. Both compounds were synthesized in good yield following the previously reported approach in the analogous synthesis of compound $1 .{ }^{40}$ Condensation of either 4-methoxyphenylphosphonic acid or phenylphosphonic acid with the lacunary precursor 
$\mathrm{K}_{10}\left[\mathrm{P}_{2} \mathrm{~W}_{17} \mathrm{O}_{61}\right] \cdot 20 \mathrm{H}_{2} \mathrm{O}$ in $N, N^{\prime}$-dimethylacetamide (DMA) yielded an orange or pale green powder, respectively, which was subsequently recrystallized via dissolution in 6:1 acetonitrile/water solution and slow evaporation of the resulting liquor over a period of $c a .2$ weeks.

Single crystal X-ray diffraction studies revealed that both compounds crystallize in the triclinic crystal system with space group $P-1$. All three hybrid-POM clusters effectively share the same structural motif, where two organophosphonate ligands occupy the lacunary site in the vacant cap position of the oxoanion. These are orientated such that the organic components protrude from the metal oxide core in opposing directions whilst the terminal $\mathrm{P}=\mathrm{O}$ positions are aligned to form a bis-phosphonate moiety which associates with a $\mathrm{K}^{+}$ion in the crystal structures of both $\mathbf{2}$ and 3. The composition of $\mathbf{2}$ and $\mathbf{3}$ was confirmed by elemental analyses, FTIR, ESI-MS, ${ }^{1} \mathrm{H}$ and ${ }^{31}$ P NMR (full details can be found in the experimental section and accompanying SI).

\section{Spectroscopic and Electrochemical Analysis}

Based on the qualitative DFT calculations above, it can be expected that both the electrochemical and the optical properties of the hybridized clusters should be altered (through tuning of the LUMO energy and the magnitude of the $\mathrm{HL}_{\text {gap }}$, respectively). In practice, we have previously found that it is difficult to correlate the simulated characteristics of the POMs with their measured absorption spectra. This is likely due to the complex optical behavior of these species, as evidenced by the very broad UV absorption bands which correspond to the characteristic $\mathrm{O} \rightarrow$ W LMCT transitions (see discussion above). Here, whilst the spectrum of compounds $\mathbf{1 - 3}$ show unique features in the UV region below $350 \mathrm{~nm}$ (Figure S10), the absorption tail of these hybrids extending into the visible region of the spectra is found to be broadly similar, both to each other 
and to the parent $\left\{\mathbf{P}_{\mathbf{2}} \mathbf{W}_{\mathbf{1 8}}\right\}$ anion. It is therefore difficult to ascribe any significance to ligandmediated effects in such experiments. One minor exception is the notable red-shift observed above $c a .370 \mathrm{~nm}$ in the methoxy-functionalized hybrid, $\mathbf{3}$, which may arise from overlapping, lower energy ligand $\rightarrow$ ligand transitions (note the anomalously high energy, ligand methoxycentered HOMO state in Figures 2 and S7).

Whilst the absorption characteristics of these hybrid POM species are therefore not expected to be particularly diagnostic of their effectiveness as photocatalysts (other than to say that all hybrids show moderate absorption in the high-energy region of the visible spectrum), our previous work suggests that their electrochemical properties can provide an effective measure of their overall performance as photocatalysts. Note that whilst the electrochemical effects of grafting organic groups onto the structure of polyoxometalates is relatively well-established (leading to positive redox shifts of up to $500 \mathrm{mV}$ over their parent compounds), ${ }^{53,54}$ this is generally limited to a broad comparison between the anchoring main group elements present (i.e. $\mathrm{P}$ or $\mathrm{Si}$ ) rather than the nature of the organic component itself. This report is therefore the first example, of which we are aware, where a systematic study has been performed on the effects that the electronic character of the ligand alone can exert directly over the metal-oxide core.

Cyclic voltammetry (CV) was performed on compounds $\mathbf{2}$ and $\mathbf{3}$ in dry DMF under a positive pressure of $\mathrm{N}_{2}$ and the results were compared to those previously reported for $\mathbf{1}$. In both cases, three quasi-reversible redox couples, each corresponding to one-electron $\mathrm{W}^{\mathrm{VI}} / \mathrm{W}^{\mathrm{V}}$ processes, were observed in the potential range of 0.5 to $-1.3 \mathrm{~V}$, which agrees well with that observed for 1 (Figure 3a, Table 1 and SI). Comparison of the $E_{1 / 2}$ values observed for the first redox couple in each case, however, provides clear evidence for a ligand-mediated effect whereby values of $-254 \mathrm{mV},-268 \mathrm{mV}$ and $-285 \mathrm{mV}$ ( $v s . \mathrm{SCE}$ ) were identified for compounds $\mathbf{1}, \mathbf{2}$ and $\mathbf{3}$, 
A)

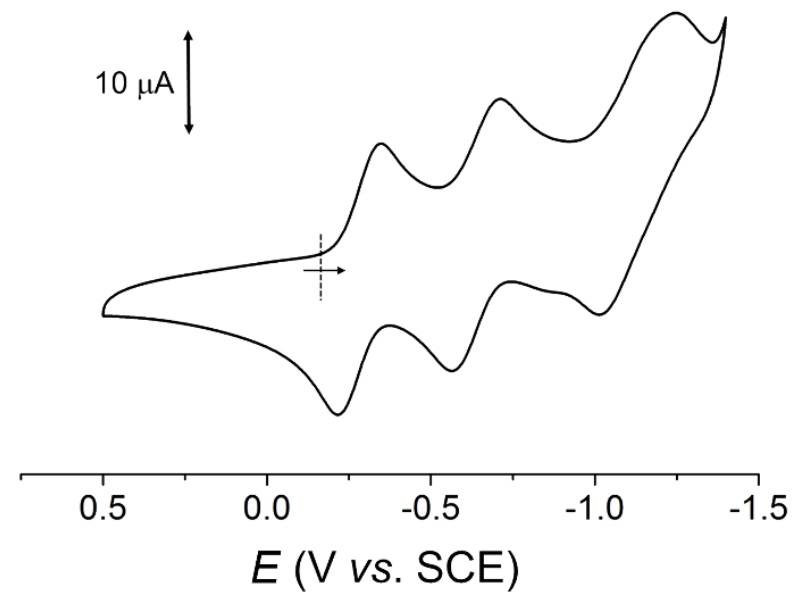

B)

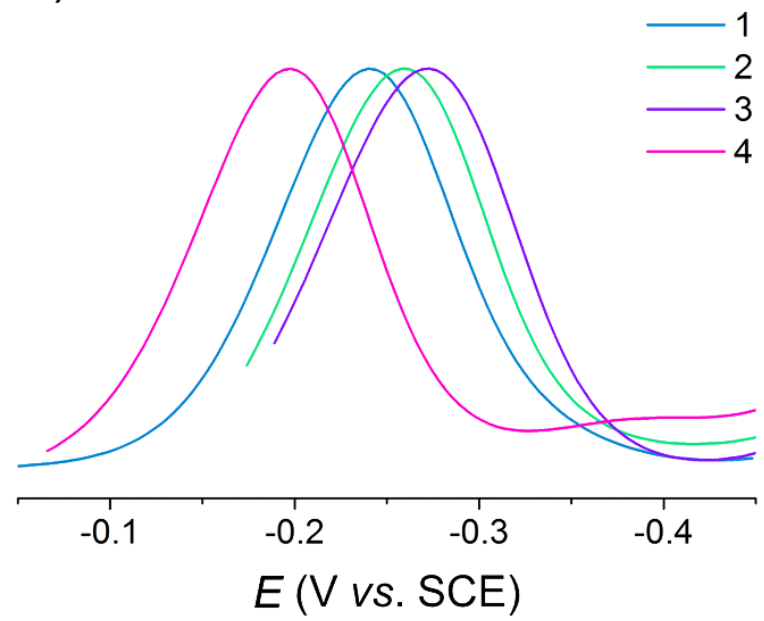

Figure 3. Electrochemical characterization of compounds 1-4 showing: a) Cyclic voltammogram of compound 3 (as representative of compounds 1-4), with the scan direction and native potential highlighted and; b) Differential pulsed voltammograms of compounds 1-4, highlighting the first reduction wave of each species. Note that current has been plotted on an arbitrary scale to aid comparison.

respectively. Differential pulsed voltammetry (DPV) experiments also confirm that the first reduction wave of each hybrid is shifted towards increasingly negative potentials on moving from 1 to 3 (Figure 3b). This trend correlates strongly with our hypothesis that the LUMO of the metal-oxide core should be destabilized upon increasing the electron-donating character of the para-substituent group and shows, unambiguously, that the nature of the appended ligand group can thus be used as a synthetic tool to tune the physical properties of the POM core. 
Table 1. Observed halfwave redox potentials $\left(E_{1 / 2}\right)^{\mathrm{a}}$ and peak cathodic potentials $\left(E_{\mathrm{pc}}\right)$ for the first reduction of compounds 1-4 (as obtained by differential pulsed voltammetry). All potentials reported vs. SCE.

\begin{tabular}{cllll}
\hline & $\boldsymbol{E}_{\mathbf{1} / \mathbf{2}}\left(\mathbf{1}^{\mathbf{s t}}\right) / \mathbf{V}$ & $\boldsymbol{E}_{\mathbf{p c}}\left(\mathbf{1}^{\mathrm{st}}\right) / \mathbf{V}$ & $\boldsymbol{E}_{\mathbf{1} / \mathbf{2}}\left(\mathbf{2}^{\mathbf{n d}}\right) / \mathbf{V}$ & $\boldsymbol{E}_{\mathbf{1} / \mathbf{2}}\left(\mathbf{3}^{\mathrm{rd}}\right) / \mathbf{V}$ \\
\hline $\mathbf{1}$ & -0.25 & -0.24 & -0.63 & -1.09 \\
\hline $\mathbf{2}$ & -0.26 & -0.26 & -0.62 & -1.08 \\
\hline $\mathbf{3}$ & & & & -1.12 \\
\hline $\mathbf{4}$ & -0.28 & -0.27 & -0.64 & -0.94 \\
\hline
\end{tabular}

${ }^{\mathrm{a}} E_{1 / 2}=\left(E_{\mathrm{pc}}+E_{\mathrm{pa}}\right) / 2 .\left(E_{\mathrm{pa}}=\right.$ peak anodic potential $)$

\section{Modified Substituent Effects in a Phosphonic-acid Substituted POM}

As an extension of this study, we turned our attention to the exploration of a fourth compound, $\mathrm{K}_{6}\left[\mathrm{P}_{2} \mathrm{~W}_{17} \mathrm{O}_{61}(\mathrm{P}(=\mathrm{O}) \mathrm{H})_{2}\right](4)$, where the organophosphonate moiety has been replaced by purely inorganic phosphonic acid groups. In this case, the ligand group is expected to exert an electron withdrawing/inductive effect on the POM core but minimal resonance effects in the absence of an aromatic component, allowing us to develop a clearer idea of the electronic factors most important to the control of the POM's photocatalytic properties.

Compound $\mathbf{4}$ was synthesized using the same method as described for $\mathbf{2}$ and $\mathbf{3}$ above and, whilst it was not possible to isolate single crystals suitable for structural analysis, 4 was unambiguously characterized by elemental analysis, ESI-MS, ${ }^{1} \mathrm{H}$ and ${ }^{31} \mathrm{P}$ NMR. This analysis reveals that $\mathbf{4}$ can be considered an all-inorganic structural analogue of the hybrid clusters 1-3. 
The UV-vis absorption characteristics of $\mathbf{4}$ are broadly in-line with that reported for compounds 1-3 and $\left\{\mathbf{P}_{2} \mathbf{W}_{18}\right\}$ as discussed above (see SI) and indicate that $\mathbf{4}$ is also able to absorb light in the high energy region of the visible spectrum $(\lambda<450 \mathrm{~nm})$. Cyclic voltammetry of 4 performed in dry DMF under an atmosphere of $\mathrm{N}_{2}$ showed three quasi-reversible redox waves in the potential range of 0.5 to $-1.3 \mathrm{~V}$, indicating the same electrochemical behavior as discussed above for compounds 1-3 (Figure 3 and S14). In the case of compound 4 however, a substantial positive shift in the potential of the first redox couple was observed, with an $E_{1 / 2}$ value of -212 $\mathrm{mV} v s$. SCE (in comparison to a value of $-254 \mathrm{mV}$ in $\mathbf{1}$, for instance). As before, DPV analysis supports that the first reduction of $\mathbf{4}$ occurs at more positive potentials than the same processes in compounds 1-3 (Figure 3b). This is particularly significant given that previous results suggest that the increasingly negative potentials observed on moving from compound $\mathbf{1}$ to $\mathbf{3}$ in the results reported above are expected to adversely impact the photocatalytic properties of these hybrid POM species.

Supporting DFT calculations of the frontier energy levels in $\mathbf{4}$ confirm that the LUMO stabilizing inductive effect of the ligand group is retained by the phosphonic acid moieties, however the HOMO destabilizing resonance effects are absent (Figure S4). As a result, whilst the LUMO level is stabilized relative to $\left\{\mathbf{P}_{\mathbf{2}} \mathbf{W}_{18}\right\}$ and is found at a similar energy to that of compound 1, the HOMO energy in $\mathbf{4}$ is also much lower lying than that of the hybrid complexes $(\mathbf{1}, \mathbf{2}$, and $\mathbf{3})$ and is more comparable to that found in $\left\{\mathbf{P}_{\mathbf{2}} \mathbf{W}_{\mathbf{1 8}}\right\}$. In addition, the orbital character observed in compound $\mathbf{4}$, whist still mixed between the phosphonate and POM, is much more strongly localized on the metal-oxide shell than is the case for compounds 1-3 (see Fig S5-8), which show significant contribution from the ligand groups in the HOMO- $n$ levels. Whilst the $\mathrm{HL}_{\text {gap }}$ in $\mathbf{4}$ is theoretically larger than that observed in compounds $\mathbf{1 - 3}$, experimentally this is 
shown to have a negligible effect on the absorption 'tail' of the cluster into the visible region of the spectrum (between $400-450 \mathrm{~nm}$ ). Taken together, these results indicate that 4 should be a promising compound for further study in photocatalytic experiments.

\section{Solution Stability and Hydrolysis Behavior}

Prior to a comparison of the photocatalytic properties of $\mathbf{1 - 4}$, it was important to address longstanding questions about the stability of organophosphonate POMs in solution (particularly in relation to the ease with which the P-O bonds in these systems may be hydrolyzed in the presence of water). ${ }^{55}$ The stability of compounds 1-4 was studied using comprehensive ${ }^{31} \mathrm{P}$ NMR analysis, the results of which are presented in the SI. In the case of compounds $\mathbf{1 - 3}$, and in agreement with our previous findings, ${ }^{56}{ }^{31} \mathrm{P}$ NMR spectra show no decomposition after 24 hours in both DMSO- $\mathrm{d}_{6}$ and $\mathrm{D}_{2} \mathrm{O}$, indicating good stability in both solvents.

In the case of compound $\mathbf{4}$ however, a more complicated behaviour emerges in the presence of water/ $\mathrm{D}_{2} \mathrm{O}$. Whilst the ${ }^{31} \mathrm{P}$ NMR of 4 measured in DMSO- $\mathrm{d}_{6}$ shows the same behaviour as described above for 1-3, identical measurements performed after 24 hours in $\mathrm{D}_{2} \mathrm{O}$ show the formation of new peaks in the regions of the spectrum corresponding to both the ligand and POM-templating phosphorous nuclei (Figure S19). Both observations show that the phosphonate groups on $\mathbf{4}$ are being gradually hydrolyzed, producing free phosphonic acid and leading to the conversion of the lacunary $\left\{\mathrm{P}_{2} \mathrm{~W}_{17}\right\}$ cluster into the more thermodynamically stable $\left\{\mathrm{P}_{2} \mathrm{~W}_{18}\right\}$ species (possibly aided by the liberation of acidic protons from free phosphonic acid). ${ }^{31} \mathrm{P}$ NMR measurement of the same solution after 1 week confirms this, showing total loss of the signals originating from 4. Interestingly, the same NMR experiments performed in mixed solvent $(10 \%$ $\mathrm{H}_{2} \mathrm{O}$ by volume in DMSO- $\mathrm{d}_{6}$ ) show no decomposition, indicating that the hydrolytic 
decomposition of $\mathbf{4}$ is equilibrium controlled and the rate dependent on the quantity of water present. Complementary ESI-MS analysis was also used to characterize the speciation of $\mathbf{4}$ in response to purely organic, aqueous and mixed (50:50 v/v acetonitrile:water) solvent systems (see SI for full details) and these results are in good agreement with the NMR analysis provided above, where a combined ion count analysis ${ }^{57}$ is used to show the solvent dependent speciation of 4 corresponding to its stepwise hydrolysis in the presence of $\mathrm{H}_{2} \mathrm{O}$.

These results therefore have significant implications for the use of organophosphonate functionalized POMs in real-world applications, such as photochemical reactions. Contrary to previous studies of related phosphonate-substituted POM species, all four compounds reported here show good stability in organic media and notably only the most labile species, 4 , shows time-dependent hydrolytic decomposition in the presence of high water content $(>10 \%$ by volume).

\section{Photocatalytic Properties}

Given the results described above, we were interested to explore the comparative effectiveness of compounds 2-4 as photocatalysts in relation to our previously reported studies on compounds $\mathbf{1}$ and $\left\{\mathbf{P}_{2} \mathbf{W}_{18}\right\}$. Recently, both we and others have employed soluble organic dyes as useful model pollutant compounds for the benchmarking of a variety of POM species as homogeneous catalysts. ${ }^{58-61} N, N^{\prime}$-dimethylformamide (DMF) solutions of indigo dye $(20 \mu \mathrm{M})$ - a common textile industry waste product - and the appropriate POM catalyst $(4 \mu \mathrm{M})$ were irradiated under white-light using a Xe-lamp equipped with either a 390 or $420 \mathrm{~nm}$ cut-off filter. Subsequent UVvis analysis was then employed at timed intervals to follow the decomposition of indigo by tracking its characteristic absorption signal at $613 \mathrm{~nm}$. The results of these experiments are 
presented in Figures 4 and S23. Taken as a representative example, the pseudo-first order rate constants extracted from the data measured at $\lambda>420 \mathrm{~nm}$ show that each species is capable of the catalytic decomposition of the dye substrate, whereby the reaction rate follows the order: $4>$ $\mathbf{1}>\mathbf{2}>\mathbf{3}>\left\{\mathbf{P}_{2} \mathbf{W}_{18}\right\}$ and is comparable to that observed for molecular cerium vanadium oxide clusters. ${ }^{58}$ These observations are replicated in the measurements performed at $\lambda>390 \mathrm{~nm}$, where the trend holds, and the stronger absorption of the POM O $\rightarrow$ W LMCT band at lower wavelengths leads to faster rates of indigo oxidation for all five of the POM species (Table 2).

Operating under the reasonable assumption that $\mathbf{2}$ and $\mathbf{3}$ are directly comparable with compound 1, the stability of the hybrid organophosphonate substituted POMs under turnover conditions has been previously confirmed..$^{40}$ In the case of the demonstrably more labile

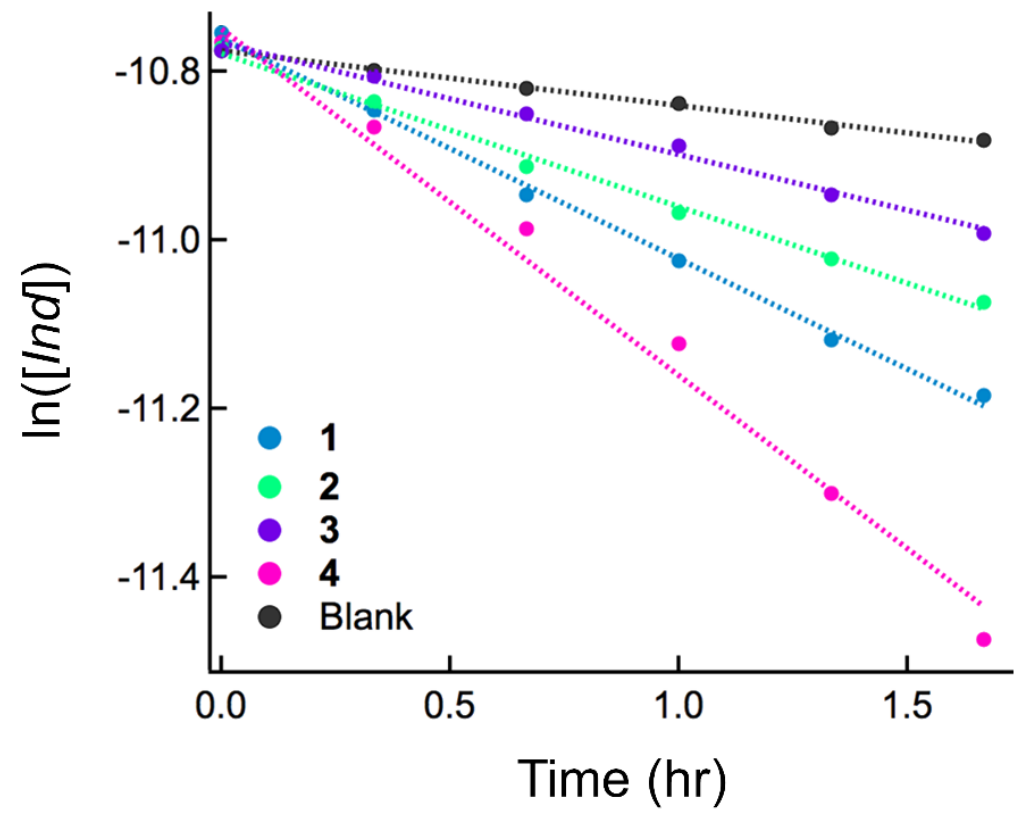

Figure 4. Pseudo-first order plot of the time-dependent photo-oxidation of indigo (Ind) in the presence of POM catalysts 1-4 (measured in DMF with irradiation at $\lambda>420$ ). A blank reaction is also performed in the absence of catalyst. 
Table 2. Pseudo-first order rate constants for the photocatalytic decomposition of indigo dye.

\begin{tabular}{lll}
\hline & Kobs $(>\mathbf{3 9 0} \mathbf{n m}) / \mathbf{s}^{-1}$ & Kobs $(>\mathbf{4 2 0} \mathbf{n m}) / \mathbf{s}^{-1}$ \\
\hline $\mathbf{1}$ & $1.1 \times 10^{-3}$ & $7.3 \times 10^{-5}$ \\
\hline $\mathbf{2}$ & $8.1 \times 10^{-4}$ & $5.0 \times 10^{-5}$ \\
\hline $\mathbf{3}$ & $6.7 \times 10^{-4}$ & $3.8 \times 10^{-5}$ \\
\hline $\mathbf{4}$ & $1.4 \times 10^{-3}$ & $1.2 \times 10^{-4}$ \\
\hline Blank & $1.8 \times 10^{-5}$ & $1.8 \times 10^{-5}$ \\
\hline$\left\{\mathbf{P}_{2} \mathbf{W}_{17}\right\}$ & $1.0 \times 10^{-4}$ & $1.1 \times 10^{-5}$ \\
\hline$\left\{\mathbf{P}_{2} \mathbf{W}_{18}\right\}$ & $3.4 \times 10^{-4}$ & $3.0 \times 10^{-5}$ \\
\hline
\end{tabular}

inorganic species, 4 , we performed both catalyst recycling and ${ }^{31} \mathrm{P}$ NMR experiments to assess its stability during the course of the indigo oxidation reaction (see SI for details). Recycling experiments confirm that $\mathbf{4}$ retains its full catalytic performance over three consecutive reaction cycles whilst ${ }^{31} \mathrm{P}$ NMR measurements confirm the stability of $\mathbf{4}$ after decolouration of a more concentrated reaction solution $(1 \mathrm{mM} \mathrm{4,10} \mathrm{mM} \mathrm{indigo,} \lambda>390 \mathrm{~nm}, \mathrm{t}=24 \mathrm{~h})$. This shows that, in the absence of significant water content, 4 remains stable over multiple photocatalytic oxidation reactions.

These measurements highlight a clear trend which correlates remarkably strongly with the theoretical and electrochemical observations presented above. In the first instance, the systematic 'orbital engineering' strategy we propose here is fully experimentally validated, where the rate of indigo oxidation is exactly as expected based on the strength of the electron-withdrawing character of the para-substituent $\left(\right.$ i.e. $\left.\mathbf{1}(-\mathrm{COOH})>\mathbf{2}(-\mathrm{H})>\mathbf{3}\left(-\mathrm{OCH}_{3}\right)\right)$. 


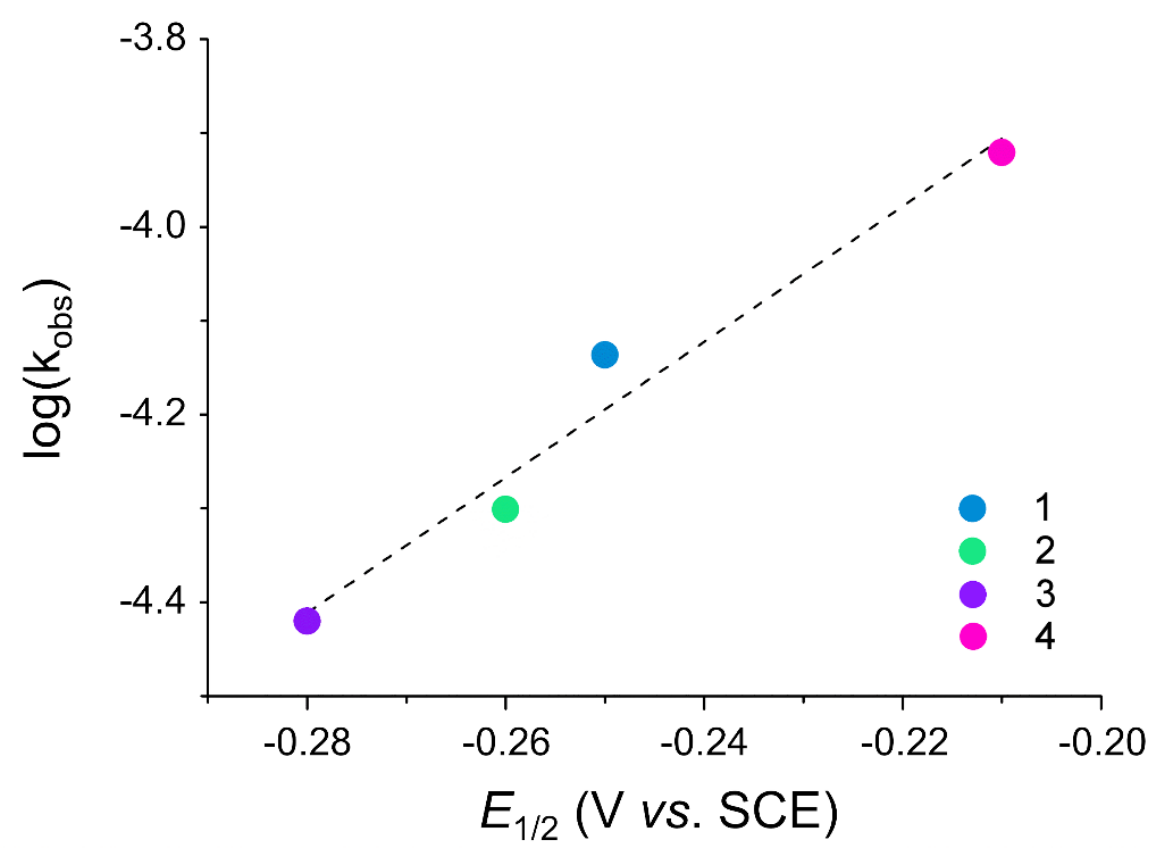

Figure 5. Plot showing the linear correlation between the first reduction $E_{1 / 2}$ values of 1-4 (see Table 1) and the logarithm of the rate of indigo oxidation $(\lambda>420 \mathrm{~nm}$ ) (as taken from Figure 4, above).

In the second instance, the superior photocatalytic properties of $\mathbf{4}$ can be explained in large part by its more positive first redox potential, arising as a result of the inductive stabilization of the LUMO level by complexation of the POM core with electron-withdrawing phosphonic acid moieties. Whilst the corresponding destabilization of the HOMO level via resonance effects is not observed due to the lack of aromaticity in $\mathbf{4}$, it is interesting to note that this is not found to be detrimental to its photocatalytic performance.

In addition, it is revealing that the rate constants described above show a linear relationship with the $E_{1 / 2}$ values of the first redox couple in each species (see Figures 5 and S24). This indicates that the electrochemical properties (specifically the LUMO energies) of these 
phosphonate-substituted clusters are key determinants of catalytic performance. The relationship also indicates that steric factors (due to the reduced size of the ligand component) are not responsible for the improved performance of 4 . That the redox properties can be readily tuned by the substitution of different ligand moieties on the metal-oxide shell indicates that this could be a powerful new strategy in the direct visible-light photo-activation of POM clusters and will be broadly applicable across a wide range of molecular metal oxide and ligand types, opening the door to the targeted molecular design of next-generation supramolecular and multi-functional POM-based photochemical constructs.

\section{Conclusions}

In summary, we have demonstrated a new strategy for the direct photo-activation of polyoxometalate clusters via their facile hybridization with a range of phosphonate-derived substituents. By altering the properties of the covalently-bound substituent groups, we show that an orbital engineering approach can be used to controllably modify the properties of the metaloxide cluster. This is shown to have significant implications for the photo-reactivity of the substituted clusters, effectively 'activating' the photo-oxidative response of the POM towards a model organic substrate under visible light irradiation. The degree of this activation is found to be entirely dependent on the inductive (i.e. electron-withdrawing) properties of the substituent groups that are appended to the metal-oxide core, where comparatively small modifications to the electronic properties of the POM core result in dramatic differences in their photocatalytic ability. For example, a relatively modest shift of $73 \mathrm{mV}$ in the half-wave potential corresponding to the first redox waves in compounds $\mathbf{3}$ and $\mathbf{4}$ results in a tripling of the observed rate of indigo 
decomposition under visible light irradiation $(\lambda>420 \mathrm{~nm})$, indicating there is significant further scope for development of this approach.

Uniquely, this strategy allows the inherent photochemistry of the POM core to be addressed directly and facilitates the generation of catalytically active oxo-centred radicals on the metaloxide shell using irradiation with visible light. This differs significantly from previous approaches which rely on the use of secondary chromophore species to facilitate inter- or intramolecular charge-transfer to the POM core rather than the generation of a reactive chargeseparated state on it. This feature therefore potentially opens the door to a wide range of new visible-light driven oxidation and hydrogen-transfer reactivity in tungsten-based hybrid systems. Furthermore, we also note that functionalization with phosphonate moieties is shown to result in robust complexes which have been demonstrated to be stable in both organic and aqueous media and, crucially, during catalytic turnover conditions. We propose that this new orbital engineering strategy should therefore have significant implications for the design and optimization of a new class of visible-light driven hybrid-POM photocatalysts. Given the enormous future potential for additional ligand design, control of supramolecular interactions and cluster optimization, we believe this broadly applicable strategy should lead to significant advances in the generation of novel POM-based photo-active materials.

\section{ASSOCIATED CONTENT}

Supporting Information is available free of charge online at DOI: $\mathrm{xxx} / \mathrm{xxxx}$ 
Full details of experimental methods and materials, crystallographic details, mass spectrometric analysis, density functional theory analysis, UV-vis absorbtion spectroscopic analysis, electrochemical analysis, stability studies and catalytic photo-oxidation studies. (PDF).

Crystallographic data files for compounds $\mathbf{2}$ and $\mathbf{3}$ have been deposited with the Cambridge Crystallographic Data Centre (CCDC accession numbers: 1535775 and 1535776).

\section{AUTHOR INFORMATION}

\section{Corresponding Authors}

Corresponding authors can be contacted at the following:

*graham.newton@nottingham.ac.uk

*oshio@chem.tsukuba.ac.jp

\section{Author Contributions}

The manuscript was written through contributions of all authors. All authors have given approval to the final version of the manuscript.

\section{ACKNOWLEDGMENT}

This work was supported by the Japan Society for the Promotion of Science, a Grant-in-Aid for Scientific Research from the Ministry of Education, Culture, Sports, Science and Technology, Japan, and by the University of Nottingham. The authors also wish to thank the University of 
Nottingham Advanced Molecular Materials Research Group for financial support and the University of Nottingham for access to the Minerva High Performance Computing suite. 


\section{REFERENCES}

1. Schultz, D.M.; Yoon, T.P. Solar Synthesis: Prospects in Visible Light Photocatalysis. Science 2014, 343, 985.

2. Ravelli, D.; Dondi, D.; Fagnoni, M.; Albini, A. Photocatalysis. A Multi-faceted Concept for Green Chemistry. Chem. Soc. Rev. 2009, 38, 1999-2011.

3. Fukuzumi, S.; Ohkubo, K. Selective Photocatalytic Reactions with Organic Photocatalysts. Chem. Sci. 2013, 4, 561-574.

4. Tran, P.D.; Wong, L.H.; Barber, J.; Loo, J.S.C. Recent Advances in Hybrid Photocatalysts for Solar Fuel Production. Energ. Environ. Sci. 2012, 5, 5902-5918.

5. Nocera, D.G. The Artificial Leaf. Accounts Chem. Res. 2012, 45, 767-776.

6. Osterloh, F.E. Inorganic Nanostructures for Photoelectrochemical and Photocatalytic Water Splitting. Chem. Soc. Rev. 2013, 42, 2294-2320.

7. Chen, X.; Li, C.; Gratzel, M.; Kostecki, R.; Mao, S.S. Nanomaterials for Renewable Energy Production and Storage. Chem. Soc. Rev. 2012, 41, 7909-7937.

8. Colmenares, J.C.; Luque, R. Heterogeneous Photocatalytic Nanomaterials: Prospects And Challenges in Selective Transformations of Biomass-derived Compounds. Chem. Soc. Rev. 2014, 43, 765-778.

9. Esswein, A.J.; Nocera, D.G. Hydrogen Production by Molecular Photocatalysis. Chem. Rev. 2007, 107, 4022-4047. 
10. Morris, A.J.; Meyer, G.J.; Fujita, E. Molecular Approaches to the Photocatalytic Reduction of Carbon Dioxide for Solar Fuels. Accounts Chem. Res. 2009, 42, 1983-1994.

11. Sartorel, A.; Bonchio, M.; Campagna, S.; Scandola, F. Tetrametallic Molecular Catalysts for Photochemical Water Oxidation. Chem. Soc. Rev. 2013, 42, 2262-2280.

12. Huo, H.; Shen, X.; Wang, C.; Zhang, L.; Rose, P.; Chen, L.-A.; Harms, K.; Marsch, M.; Hilt, G.; Meggers, E. Asymmetric Photoredox Transition-metal Catalysis Activated by Visible Light. Nature 2014, 515, 100-103.

13. Pope, M.T.; Müller, A. Polyoxometalate Chemistry: An Old Field with New Dimensions in Several Disciplines. Angew. Chem. Int. Ed. 1991, 30, 34-48.

14. Long, D.-L.; Tsunashima, R.; Cronin, L. Polyoxometalates: Building Blocks for Functional Nanoscale Systems. Angew. Chem. Int. Ed. 2010, 49, 1736-1758.

15. Symes, M.D.; Cronin, L. Decoupling Hydrogen and Oxygen Evolution During Electrolytic Water Splitting Using an Electron-Coupled-Proton Buffer. Nature Chem. 2013, 5, 403-409.

16. Sumliner, J.M.; Lv, H.; Fielden, J.; Geletii, Y.V.; Hill, C.L. Polyoxometalate MultiElectron-Transfer Catalytic Systems for Water Splitting. Eur. J. Inorg. Chem. 2014, 2014, 635-644.

17. Streb, C. New Trends in Polyoxometalate Photoredox Chemistry: From Photosensitisation to Water Oxidation Catalysis. Dalton Trans. 2012, 41, 1651-1659.

18. Yamase, T. Photoredox Chemistry of Polyoxometalates as a Photocatalyst. Catal. Surv. Asia 2003, 7, 203-217. 
19. Lykakis, I.N.; Evgenidou, E.; Orfanopoulos, M. Photo-catalysis and Polyoxo-anion Decatungstate in Organic Chemistry: A Manifold Concept for Green Chemistry. Curr. Org. Chem. 2012, 16, 2400-2414.

20. Tzirakis, M.D.; Lykakis, I.N.; Orfanopoulos, M. Decatungstate as an Efficient Photocatalyst in Organic Chemistry. Chem. Soc. Rev. 2009, 38, 2609-2621.

21. Halperin, S.D.; Fan, H.; Chang, S.; Martin, R.E.; Britton, R. A Convenient Photocatalytic Fluorination of Unactivated C-H Bonds. Angew. Chem. Int. Ed. 2014, 53, 4690-4693.

22. Bassil, B.S.; Kortz, U. Divacant Polyoxotungstates: Reactivity of the Gammadecatungstates $\left[\gamma-\mathrm{XW}_{10} \mathrm{O}_{36}\right]^{8-}(\mathrm{X}=\mathrm{Si}, \mathrm{Ge})$. Dalton Trans. 2011, 40, 9649-9661.

23. Miras, H.N.; Yan, J.; Long, D.L.; Cronin, L. Engineering Polyoxometalates with Emergent Properties. Chem. Soc. Rev. 2012, 41, 7403-7430.

24. Oms, O.; Dolbecq, A.; Mialane, P. Diversity in Structures and Properties of 3dIncorporating Polyoxotungstates. Chem. Soc. Rev. 2012, 41, 7497-7536.

25. Kortz, U.; Müller, A.; van Slageren, J.; Schnack, J.; Dalal, N.S.; Dressel, M. Polyoxometalates: Fascinating Structures, Unique Magnetic Properties. Coord. Chem. Rev. 2009, 253, 2315-2327.

26. Wang, S.-S.; Yang, G.-Y. Recent Advances in Polyoxometalate-Catalyzed Reactions. Chem. Rev. 2015, 115, 4893-4962.

27. Ritchie, C.; Moore, E.G.; Speldrich, M.; Kögerler, P.; Boskovic, C. Terbium Polyoxometalate Organic Complexes: Correlation of Structure with Luminescence Properties. Angew. Chem. Int. Ed. 2010, 49, 7702-7705. 
28. Song, Y.-F.; Tsunashima, R. Recent Advances on Polyoxometalate-based Molecular and Composite Materials. Chem. Soc. Rev. 2012, 41, 7384-7402.

29. Dolbecq, A.; Dumas, E.; Mayer, C.R.; Mialane, P. Hybrid Organic-Inorganic Polyoxometalate Compounds: From Structural Diversity to Applications. Chem. Rev. 2010, 110, 6009-6048.

30. Proust, A.; Matt, B.; Villanneau, R.; Guillemot, G.; Gouzerh, P.; Izzet, G. Functionalization and Post-functionalization: A Step Towards Polyoxometalate-based Materials. Chem. Soc. Rev. 2012, 41, 7605-7622.

31. Santoni, M.-P.; Hanan, G.S.; Hasenknopf, B. Covalent Multi-component Systems of Polyoxometalates and Metal Complexes: Toward Multi-Functional Organic-inorganic Hybrids in Molecular and Material Sciences. Coord. Chem. Rev. 2014, 281, 64-85.

32. Izzet, G.; Abécassis, B.; Brouri, D.; Piot, M.; Matt, B.; Serapian, S.A.; Bo, C.; Proust, A. Hierarchical Self-Assembly of Polyoxometalate-Based Hybrids Driven by Metal Coordination and Electrostatic Interactions: From Discrete Supramolecular Species to Dense Monodisperse Nanoparticles. J. Am. Chem. Soc. 2016, 138, 5093-5099.

33. Matt, B.; Coudret, C.; Viala, C.; Jouvenot, D.; Loiseau, F.; Izzet, G.; Proust, A. Elaboration of Covalently Linked Polyoxometalates with Ruthenium and Pyrene Chromophores and Characterization of Their Photophysical Properties. Inorg. Chem. 2011, 50, 7761-7768. 
34. Santoni, M.-P.; Pal, A.K.; Hanan, G.S.; Tang, M.-C.; Furtos, A.; Hasenknopf, B. A Light-harvesting Polyoxometalate-polypyridine Hybrid Induces Electron Transfer as its Re(I) Complex. Dalton Trans. 2014, 43, 6990-6993.

35. Fay, N.; Hultgren, V.M.; Wedd, A.G.; Keyes, T.E.; Forster, R.J.; Leane, D.; Bond, A.M. Sensitization of Photo-reduction of the Polyoxometalate Anions $\mathrm{S}_{2} \mathrm{M}_{18} \mathrm{O}_{62}$ (4-) ( $\mathrm{M}=\mathrm{Mo}$, W) in the Visible Spectral Region by the $\mathrm{Ru}(\mathrm{bpy})_{3}(2+)$ Cation. Dalton Trans. 2006, $4218-4227$.

36. Walsh, J.J.; Bond, A.M.; Forster, R.J.; Keyes, T.E. Hybrid Polyoxometalate Materials for Photo(Electro-) Chemical Applications. Coord. Chem. Rev. 2016, 306, Part 1, 217-234.

37. Suzuki, K.; Jeong, J.; Yamaguchi, K.; Mizuno, N. Visible-light-responsive Multielectron Redox Catalysis of Lacunary Polyoxometalates Induced by Substrate Coordination to Their Lacuna. Chem. Asian. J. 2015, 10, 144-148.

38. Rinfray, C.; Renaudineau, S.; Izzet, G.; Proust, A. A Covalent Polyoxomolybdate-based Hybrid with Remarkable Electron Reservoir Properties. Chem. Commun. 2014, 50, 85758577.

39. Matt, B.; Fize, J.; Moussa, J.; Amouri, H.; Pereira, A.; Artero, V.; Izzet, G.; Proust, A. Charge photo-accumulation and photocatalytic hydrogen evolution under visible light at an iridium(III)-photosensitized polyoxotungstate. Energy Environ. Sci., 2013, 6, 15041508. 
40. Cameron, J.M.; Fujimoto, S.; Kastner, K.; Wei, R.-J.; Robinson, D.; Sans, V.; Newton, G.N.; Oshio, H.H. Orbital Engineering: Photoactivation of an Organofunctionalized Polyoxotungstate. Chem. Eur. J. 2017, 23, 47-50.

41. Mohapatra, S., and Pramanik, P. Synthesis and stability of functionalized iron oxide nanoparticles using organophosphorus coupling agents. Colloid Surf. A - Physicochem. Eng. Asp. 2009, 339, 35-42.

42. Contant, R.; Klemperer, W. G.; Yaghi, O., Potassium Octadecatungstodiphosphates(V) and Related Lacunary Compounds. In Inorganic Syntheses, John Wiley \& Sons, Inc.: 2007; pp 104-111.

43. Sheldrick, G. A short history of SHELX. Acta Crystallogr., Sect. A: Found. Crystallogr. 2008, 64, 112-122.

44. Spek, A.L. PLATON SQUEEZE: a tool for the calculation of the disordered solvent contribution to the calculated structure factors. Acta Crystallogr. Sect. C-Struct. Chem. 2015, 71, 9-18.

45. Becke, A.D. Density Functional Calculations of Molecular-bond Energies. J. Chem. Phys. 1986, 84, 4524-4529.

46. Perdew, J.P. Density-functional Approximation for the Correlation-energy of the Inhomogeneous Electron-gas. Phys. Rev. B 1986, 33, 8822-8824.

47. Hay, P.J.; Wadt, W.R. Abinitio Effective Core Potentials for Molecular Calculations Potentials for K to Au Including the Outermost Core Orbitals. J. Chem. Phys. 1985, 82, 299-310. 
48. Andrae, D.; Haussermann, U.; Dolg, M.; Stoll, H.; Preuss, H. Energy-adjusted Abinitio Pseudopotentials for the 2nd and 3rd Row Transition-Elements. Theor. Chim. Acta. 1990, $77,123-141$.

49. Shao, Y.H.; Gan, Z.T.; Epifanovsky, E.; Gilbert, A.T.B.; Wormit, M.; Kussmann, J.; Lange, A.W.; Behn, A.; Deng, J.; Feng, X.T.; et al.. Advances in molecular quantum chemistry contained in the Q-Chem 4 program package. Mol. Phys. 2015, 113, 184-215.

50. Becke, A.D. Density-functional Exchange-energy Approximation with Correct Asymptotic-behavior. Phys. Rev. A 1988, 38, 3098-3100.

51. Lopez, X.; Carbo, J.J.; Bo, C.; Poblet, J.M. Structure, Properties and Reactivity of Polyoxometalates: A Theoretical Perspective. Chem. Soc. Rev. 2012, 41, 7537-7571.

52. While the TDDFT oscillator strengths are calculated from the transition dipole moment of the electronic excitations, they can be linked to experimental absorption spectra by considering the transition as a classical oscillating dipole. Thus, the oscillator strength, $f$, is given as: $f=4.319 \times 10^{-9} \int_{\varepsilon}(v) \mathrm{d} v$; where the integral on the right-hand side of the equation is the area under the curve of the experimental UV-vis spectrum. While the experimental $\mathrm{O} \rightarrow \mathrm{W}$ LMCT band is broad (and as such would have a large area), the TDDFT transitions reveal that several closely spaced transitions contribute to the convoluted broad band observed, and thus we can differentiate between localized organic transitions and the POM centered transitions based on the oscillator strength.

53. Agustin, D.; Dallery, J.; Coelho, C.; Proust, A.; Thouvenot, R. Synthesis, Characterization and Study of the Chromogenic Properties of the Hybrid 
Polyoxometalates $\left[\mathrm{PW}_{11} \mathrm{O}_{39}(\mathrm{SiR})_{2} \mathrm{O}\right]^{3-}\left(\mathrm{R}=\mathrm{Et}, \quad\left(\mathrm{CH}_{2}\right)_{\mathrm{n}} \mathrm{CHCH}_{2} \quad(\mathrm{n}=0,1,4)\right.$, $\left.\mathrm{CH}_{2} \mathrm{CH}_{2} \mathrm{SiEt}_{3}, \mathrm{CH}_{2} \mathrm{CH}_{2} \mathrm{SiMe}_{2} \mathrm{Ph}\right)$. J. Organomet. Chem. 2007, 692, 746-754.

54. Boujtita, M.; Boixel, J.; Blart, E.; Mayer, C.R.; Odobel, F. Redox Properties of Hybrid Dawson Type Polyoxometalates Disubstituted with Organo-silyl or Organo-phosphoryl Moieties. Polyhedron 2008, 27, 688-692.

55. Kim, G.S.; Hagen, K.S.; Hill, C.L. Synthesis, Structure, Spectroscopic Properties, And Hydrolytic Chemistry Of Organophosphonoyl Polyoxotungstates Of Formula $\left[\mathrm{C}_{6} \mathrm{H}_{5} \mathrm{P}(\mathrm{O})\right]_{2} \mathrm{X}^{\mathrm{n}+} \mathrm{W}_{11} \mathrm{O}_{39}{ }^{(8-\mathrm{n})-}\left(\mathrm{X}^{\mathrm{n}+}=\mathrm{P}^{5+}, \mathrm{Si}^{4+}\right)$. Inorg. Chem. 1992, 31, 5316-5324.

56. Kastner, K.; Kibler, A.J.; Karjalainen, E.; Fernandes J.A.; Sans V.; Newton G.N. Redoxactive organic-inorganic hybrid polyoxometalate micelles. J. Mater. Chem. A 2017, 5, $11577-11581$.

57. Cameron, J.M.; Vila-Nadal, L.; Winter, R.S.; Iijima, F.; Murillo, J.C.; Rodriguez-Fortea, A.; Oshio, H.; Poblet, J.M.; Cronin, L. Investigating the Transformations of Polyoxoanions Using Mass Spectrometry and Molecular Dynamics. J. Am. Chem. Soc. 2016, $138,8765-8773$.

58. Seliverstov, A.; Streb, C. A New Class of Homogeneous Visible-light Photocatalysts: Molecular Cerium Vanadium Oxide Clusters. Chem. Eur. J. 2014, 20, 9733-9738.

59. Tucher, J.; Peuntinger, K.; Margraf, J.T.; Clark, T.; Guldi, D.M.; Streb, C. Templatedependent Photochemical Reactivity of Molecular Metal Oxides. Chem. Eur. J. 2015, 21, 8716-8719. 
60. Kastner, K.; Forster, J.; Ida, H.; Newton, G.N.; Oshio, H.; Streb, C. Controlled Reactivity Tuning of Metal-Functionalized Vanadium Oxide Clusters, Chem. Eur. J. 2015, 21, 7686-7689.

61. Dolbecq, A.; Mialane, P.; Keita, B.; and Nadjo, L. Polyoxometalate-Based Materials for Efficient Solar and Visible Light Harvesting: Application to the Photocatalytic Degradation of Azo Dyes. J. Mater. Chem. 2012, 22, 24509-24521. 


\section{TABLE OF CONTENTS}

SYNOPSIS: Polyoxometalates (POMs) are redox and photo-active metal-oxide clusters with various potential applications in next generation nanotechnologies. Whilst the vast majority of POMs only absorb in the UV region, we present a new strategy to photo-activate the metal-oxide shell under visible light irradiation. By grafting a variety of phosphonate moieties to the POM core, we show that it is possibly to selectively tune the photo-activity of the POM via rational modification of the frontier orbital energies.

\section{FOR TABLE OF CONTENTS ONLY:}

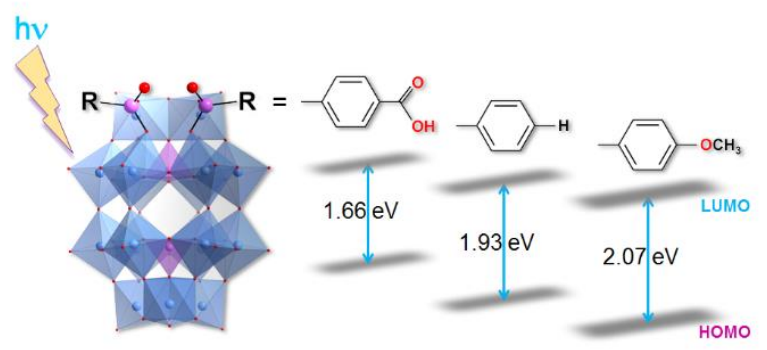

